\title{
Osteocondromatose em gato: relato de caso
}

\author{
Osteochondromatosis in a cat: case report \\ S. Winter ${ }^{1}$, T.R.Muller ${ }^{1}$, P.E. Ferian ${ }^{1}$, L.P. Souza ${ }^{1}$, M.G. Luciani ${ }^{1}$, C. Porto ${ }^{1}$, \\ R. Serakides ${ }^{2}$, W. Mai ${ }^{3}$ \\ ${ }^{1}$ Universidade do Estado de Santa Catarina - Udesc - Lages, SC \\ ${ }^{2}$ Universidade Federal de Minas Gerais - UFMG - Belo Horizonte, MG \\ ${ }^{3}$ University of Pennsylvania School of Veterinary Medicine - PennVet - Philadelphia, USA

\section{RESUMO}

A osteocondromatose é caracterizada por nódulos únicos ou múltiplos decorrentes de um crescimento ósseo excessivo benigno. É encontrada em cães, gatos, equinos e humanos. Em felinos, tem maior incidência dos dois aos quatro anos de idade. A etiologia em gatos está relacionada ao vírus da leucemia felina, e também já foi encontrada relação com o fibrossarcoma. A manifestação clínica depende do local acometido e do tamanho da lesão. O diagnóstico definitivo é por meio de histopatologia e o prognóstico é desfavorável, pois ocorrem muitas recidivas. Este relato de caso objetiva descrever a apresentação dessa enfermidade em um felino jovem.

Palavras-chave: felino, osteocondromatose, radiologia

\begin{abstract}
Osteochondromatosis is characterized by single or multiple nodules resulting from benign excessive bone growth. It is found in cats and dogs, horses and humans. In cats, a higher incidence is found in individuals from 2 to 4 years of age. The etiology in cats is related to the virus of feline leukemia, and is also related to fibrosarcoma. The clinical presentation depends on the area affected and the size of the lesion. The definitive diagnosis is by histopathology and the prognosis is poor because many relapses occur. This case report aims to describe the presentation of the disease in a young cat.
\end{abstract}

Keywords: cat, osteochondromatosis, radiology

\section{INTRODUÇ̃̃O}

A osteocondromatose é um crescimento ósseo excessivo benigno formado pela ossificação endocondral da superfície do osso e recoberto com cartilagem hialina. Esse crescimento excessivo traz distúrbios no desenvolvimento, porém, quando ocorre a maturidade óssea, ele para de aumentar (Morris e Dobson, 2007). É caracterizada pelo desenvolvimento de nódulos, que podem ser únicos (osteocondromas) ou múltiplos (osteocondromatose); a cartilagem faz encapsulamento no osso e há uma cavidade medular contínua com o osso adjacente, quando em regiões de articulações. Osteocondromatose tem sido descrita em humanos, cavalos, cães e gatos (Andreson, 2004). As áreas de predileção são vértebras, costelas, ossos longos, escápula e

Recebido em 26 de outubro de 2016

Aceito em 4 de dezembro de 2016

E-mail: tete.winter@hotmail.com pelve, entretanto há relatos de exostose cartilaginosa em traqueia (Moulton, 1978), e em gatos ainda podem ocorrer em ossos do crânio (Morris e Dobson 2007). Em felinos, geralmente é encontrado em adultos jovens de dois a quatro anos de idade (Morris e Dobson, 2007). A etiologia em gatos pode estar associada ao vírus da leucemia felina e o fibrossarcoma também tem sido encontrado em componentes cartilaginosos de osteocondromatose felina. Os sinais clínicos dependem da localização e do tamanho das alterações. Pode haver pressões sobre tendões, músculos, nervos e vasos e, consequentemente, dor e danos na fisiologia do organismo (Pool, 1950). O diagnóstico é realizado por meio da associação da anamnese, exame físico e radiografias do paciente, porém o diagnóstico definitivo é obtido por histopatologia da lesão óssea. As radiografias exibirão 
proliferações ósseas poliostóticas. O prognóstico para osteocondromatose pode ser bom, dependendo do local acometido e, quando possível, da excisão cirúrgica (osteocondroma). Contudo, essa entidade nosológica tem alto poder recidivante, e em múltiplas lesões é possível observar uma imagem de característica maligna, o que torna o prognóstico desfavorável (Morrison, 2002).

\section{RELATO DE CASO}

Um felino fêmea de pelo curto, intacta, com quatro anos de idade, apresentando aumento de volume havia seis meses, foi previamente atendido por médico veterinário de outra instituição e recebeu tratamento com administração de prednisona, via oral, $20 \mathrm{mg}$ a cada 12 horas por uma semana, seguido de $20 \mathrm{mg}$ a cada 24 horas por uma semana e, finalmente, $20 \mathrm{mg}$ em dias alternados por uma semana. Após duas semanas do tratamento inicial, o felino foi encaminhado para reavaliação no Hospital de Clínica Veterinária (HCV-CAV/UDESC) devido à falta de melhora no quadro. A palpação identificou uma formação óssea irregular na escápula direita e esquerda. Foi palpada uma massa sólida de $5 \times 7$ centímetros caudolateralmente na articulação do ombro direito. O felino não demonstrou sinais de dor durante a manipulação dos membros. A avaliação neurológica e o hemograma estavam dentro da normalidade. $\mathrm{O}$ exame radiográfico de tórax e da região escapular identificou massa óssea esclerótica e amorfa ao longo da escápula direita e esquerda, sendo o lado direito mais afetado. A nova formação óssea parece se originar dentro da escápula direita e esquerda, sem envolvimento visível da vértebra cervical ou das estruturas adjacentes. $\mathrm{O}$ contorno do córtice escapular foi obtido pela proliferação óssea ao longo do osso. Outra estrutura óssea lobulada foi identificada a partir da superfície do osso temporal direita. Foi realizada biopsia da escápula direita e esquerda. A análise histopatológica revelou uma cápsula formada por uma fina camada de tecido conjuntivo. Logo abaixo, havia uma espessa camada de tecido cartilaginoso bem diferenciado, com condroblastos isomórficos, sem atipia ou figuras mitóticas. Em direção ao centro, havia formação de tecido ósseo abaixo do tecido cartilaginoso, similar ao processo de ossificação endocondral. O tecido ósseo recém-formado apresentava padrão trabecular com várias formas e espessura. $\mathrm{O}$ osso trabecular foi coberto em alguns lugares por células fusiformes bem diferenciadas, semelhantes a osteoblastos, e não mostrou qualquer atipia e figuras de mitose. Havia raros osteoclastos. Dentro do osso trabeculado, existiam numerosos grupos de tecido conjuntivo altamente vascularizados, principalmente densos, mas ocasionalmente soltos, associados a focos ocasionais de hiperplasia mieloide. Todos esses achados suportaram o diagnóstico de osteocondromatose. Devido à impossibilidade de ressecção cirúrgica das lesões e ao prognóstico desfavorável, o gato foi eutanasiado, a pedido do proprietário.

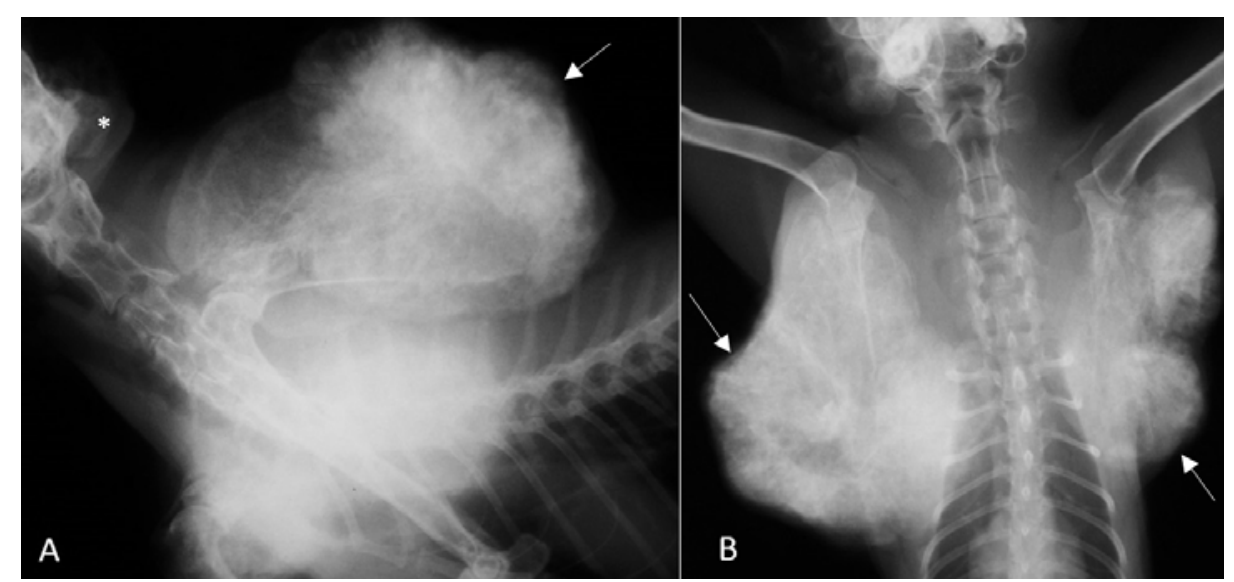

Figura 1. Radiografias de um felino fêmea, de quatro anos, nas incidências laterolateral (A) e ventrodorsal (B), apresentando acentuadas áreas de proliferação óssea caracterizando massas ósseas escleróticas que acometem escápula direita e esquerda (setas), sendo o lado direito mais afetado. * Proliferação óssea em região de occipital caudal. 


\section{DISCUSSÃO}

O felino tinha quatro anos de idade, corroborando estudos que afirmam que a prevalência é maior em gatos adultos jovens dos dois aos quatro anos de idade (Morris e Dobson, 2007). Os locais mais acometidos são vértebras, costelas, ossos longos, escápula e pelve, assim como foi visto durante a palpação nodulações em escápula direita e esquerda em região de articulação (Moulton, 1978).

$\mathrm{Na}$ radiografia, identificou-se massa óssea esclerótica e amorfa ao longo da escápula direita e esquerda, que parecia se originar dessas. Em região cortical escapular, havia proliferação óssea ao longo do osso, sendo todos esses achados condizentes com o que se observa em casos de osteocondromatose, que são crescimentos ósseos com diferentes tamanhos pela superfície do osso, contornos lisos e sem destruição ou produção óssea adjacente. Se houver alguma alteração no contorno e densidade óssea, isso pode indicar que a neoplasia não é mais benigna (Pool, 1950).

A histopatologia é o único meio de se obter um diagnóstico definitivo; onde foi observada uma cápsula com fina camada de tecido conjuntivo, abaixo havia uma camada espessa de tecido cartilaginoso bem diferenciado e, em direção ao centro, havia formação de tecido ósseo, semelhante ao processo que ocorre em ossificação endocondral. O padrão ouro histopatológico se baseia em identificar a matriz osteoide formada pelas células neoplásicas, porém o aspecto histológico varia bastante (Selvarajah e Kirpensteijn, 2010).

O tratamento só é indicado em casos que apresentarem alterações nas funções fisiológicas do organismo, ou quando o animal apresentar dor ou problemas na movimentação. Geralmente o tratamento é baseado na excisão cirúrgica, porém essa opção só é viável quando ocorrem nódulos únicos ou em locais que permitem a retirada total da lesão. A intensa proliferação óssea identificada nesse caso não viabilizou a retirada cirúrgica dos nódulos, impedindo também ampla margem cirúrgica.

\section{CONCLUSÃO}

A osteocondromatose exige estudo histopatológico da lesão óssea para diagnóstico definitivo. A avaliação radiográfica é uma importante ferramenta para estadiamento das lesões ósseas, bem como a avaliação de sua extensão e o auxílio na detecção de possíveis comorbidades. Após retirada de nódulos cirurgicamente, pode ocorrer aumento na sobrevida do paciente, contudo o prognóstico da osteocondromatose é reservado a desfavorável.

\section{REFERÊNCIAS}

ANDRESON, A.C. Multiple cartilaginous exostoses in the dog. Svensk Vet., v.15, p.13-19, 2004.

MORRIS, J.; DOBSON, J. Oncologia em pequenos animais. São Paulo: Rocca, 2007. $312 \mathrm{p}$.

MORRISON, W.B. Skeletal neoplasms. In: . Cancer in dogs \& cats: medical \& surgical management. 2.ed. Jackson, Wyoming: Teton New Media, 2002. p.621-622.

MOULTON, J.E. 2.ed. Tumors in domestic animals. London: University of California press, 1978. 465p.

POOL, R.R. Bone and cartilage. In MOULTOUN J.E. Tumors in domestic animals. [s.l.]: [s.n.], 1950. p.118-172.

SELVARAJAH， G.T.; KIRPENSTEIJN， J. Prognostic and predictive biomarkers of canine osteosarcoma. Vet. J., v.185, p.28-35, 2010. 